\title{
RESEARCH
}

Open Access

\section{YBCO as a transition metal oxide ceramic material for energy storage}

\author{
A. H. Salama ${ }^{*}$, A. M. Youssef' ${ }^{2}$, Y. S. Rammah ${ }^{3}$ and M. El-Khatib ${ }^{3}$
}

\begin{abstract}
Background: Dielectric properties and ac conductivity were studied and correlated with the structure of a series of YBCO ceramic, doped with different doping levels ranging from 0.1 to $0.5 \mathrm{wt}$ \% of magnetic nano-metal oxides, namely $\mathrm{Mn}_{3} \mathrm{O}_{4}, \mathrm{CO}_{3} \mathrm{O}_{4}$, and $\mathrm{Cr}_{2} \mathrm{O}_{3}$. The most important feature of this study was the ultrahigh values of dielectric constants at a low frequency, exactly $50 \mathrm{~Hz}$. We found that the undoped $\mathrm{YBCO}$ has a value of $\varepsilon^{\prime}$ equal to $6.99 \times 10^{6}$ at $50 \mathrm{~Hz}$ at room temperature which was increased to $1.09 \times 10^{8}$ at $120^{\circ} \mathrm{C}$, higher than any other ferroelectric material. Moreover, the value of $\varepsilon^{\prime}$ depends on the nature and the value of the magnetic moment of the doped metal oxides. The value of $\varepsilon^{\prime}$ is at least three orders of magnitude greater than any previously studied composites which suggest that this perovskite ceramic material can be used to create electrostatic capacitors with energy far better than the best electrode doublelayer capacitors (EDLC). Additionally, ac electrical conductivity has two frequency-dependent regions, the low frequency, where $\sigma_{\mathrm{ac}}$ is independent of frequency, and the high-frequency region where dispersion occurs. The ac conductivity measurement with frequency leads us to conclude that the conduction mechanism in the studied samples can be correlated barrier hopping $(\mathrm{CBH})$ model.
\end{abstract}

Results: The dielectric properties of undoped $\mathrm{YBCO}$ ceramics at $50 \mathrm{~Hz}$ in temperature ranging from room temperature to $120^{\circ} \mathrm{C}$ were studied. It is obvious that the dielectric constant and dielectric loss of YBCO decrease with increase in frequency and temperature. It can be noticed that dielectric constant of YBCO increases at $50 \mathrm{~Hz}$ from $6.99 \times 10^{6}$ at room temperature to $1.09 \times 10^{8}$ at $120^{\circ} \mathrm{C}$.

The high values of $\varepsilon^{\prime}$ recorded for $\mathrm{YBCO}$ doped with $\mathrm{Mn}_{3} \mathrm{O}_{4}$ varied from $9.45 \times 10^{5}$ to 15.5 at room temperature and $1.34 \times 10^{5}$ to 9.242 at $1 \mathrm{MHz}$ at $120^{\circ} \mathrm{C}$. For doped $\mathrm{YBCO}$ with $\mathrm{CO}_{3} \mathrm{O}_{4}$, the values of $\varepsilon \backslash$ varied from $9.5 \times 10^{5}$ at $50 \mathrm{~Hz}$ to 13.24 at $1 \mathrm{MHz}$ at room temperature, with changes from7.8 $\times 10^{4}$ at $50 \mathrm{~Hz}$ to 53.42 at $1 \mathrm{MHz}$. For YBCO ceramic samples doped with $\mathrm{Cr}_{2} \mathrm{O}_{3}$, $\varepsilon^{\prime}$ varied from $1.138 \times 10^{6}$ at $50 \mathrm{~Hz}$ to $8.38 \times 10^{3}$ at $1 \mathrm{MHz}$ at room temperature and from $5.935 \times 10^{5}$ at $50 \mathrm{~Hz}$ to $3.53 \times 10^{3}$ at $1 \mathrm{MHz}$ at $120^{\circ} \mathrm{C}$.

The ac conductivity was further studied for undoped $\mathrm{YBCO}$ and doped $\mathrm{YBCO}$ with $0.1 \mathrm{wt} . \%$ of nano-metal oxide of $\mathrm{Cr}_{2} \mathrm{O}_{3}, \mathrm{CO}_{3} \mathrm{O}_{4}$, and $\mathrm{Mn}_{3} \mathrm{O}_{4}$ samples. For all the studied samples, we found $\sigma_{\mathrm{ac}}$ is typically specified to the hopping conduction and ac conductivity has a power law behavior in terms of frequency $(\omega)$. In general, there are two frequency-dependent regions for all the studied ceramic samples; in the low-frequency region, $\sigma_{\mathrm{ac}}$ is independent of frequency whereas in the high-frequency region, dispersion occurs. The change in microwave conductivity of the studied samples with frequency $(1-5 \mathrm{MHz})$ is shown in Fig. 5. It is observed that for all samples, the conductivity increases with temperatures and depends on the doped metal oxide. The values of $\sigma_{\mathrm{ac}}$ at $5 \mathrm{MHz}$ varied from -0.4 to 1.2 for undoped $\mathrm{YBCO}$, from -0.98 to -0.75 for $0.1 \mathrm{wt} . \% \mathrm{Mn}_{3} \mathrm{O}_{4}-\mathrm{YBCO}$ sample, from -0.25 to 0.2 for $0.1 \mathrm{wt} . \%$ $\mathrm{CO}_{2} \mathrm{O}_{3}-\mathrm{YBCO}$ sample, and from -0.4 to 0.6 for $0.1 \mathrm{Wt} . \% \mathrm{Cr}_{3} \mathrm{O}_{4}-\mathrm{YBCO}$ sample.

(Continued on next page)

\footnotetext{
* Correspondence: alia2005salama@yahoo.com

${ }^{1}$ Physical Chemistry Department, National Research Centre, El-Buhouth St.,

Dokki, Cairo 12622, Egypt

Full list of author information is available at the end of the article
} 
(Continued from previous page)

Conclusion: The primary finding in this paper is of empirical investigation. YBCO, which is a high-temperature superconductor, has a high dielectric constant $\varepsilon^{\prime}$ ranging from $6.99 \times 10^{6}$ at room temperature to $1.09 \times 10^{8}$ at $120^{\circ} \mathrm{C}$. This value is at least three orders of magnitude greater than any previously studied composites which suggest that this perovskite ceramic material can be used to create electrostatic capacitors with energy far more efficient than the best electrode double layer capacitors (EDLC).

Keywords: High-temperature superconductor, Dielectric properties, Ac electrical conductivity, Super dielectric materials

\section{Background}

Hot topics like high-Tc superconductivity, ultrahigh magnet-resistance, and multi-ferrocity have been extensively studied in the last decade. These and other exciting phenomena that have been investigated in transition metal oxide.

The last two decades have brought intrinsic progress in the physics of superconductivity due to the discovery and numerous later investigations of high-temperature superconductors. Such new materials have opened the doors for endless possibilities of various applications in state-ofthe-art technologies. It is expected that the novel discoveries in this field will have an outstanding impact on electric motors, power production and transmission, transportation, and communication systems. Accordingly, there is an unmet need to promote superconducting materials and to facilitate a technological upgrade. It is therefore imperative that we develop less expensive materials which exhibit superconducting abilities at room temperature. The current focus on much of the current research is establishment and commercialization of superconductors such as YBCO. Alternatively, it is attractive to study the electrical behavior of these materials in ac fields in order to provide details regarding the transport process in the localized state of the forbidden gap (Long 1982). Dielectric measurements and ac conductivity have been discussed in the context of a wide variety of materials in order to appreciate the mechanisms of conduction processes in these materials (Abdel-All 1998; Bitar and Arafah 1998; Sedeek et al. 2003; Redwan et al. 2003; Seyam 2001; Jyothy et al. 2010; Ram et al. 2013; Atiya 2014) [2-9]. In fact, frequency-dependent electrical conductivity $\left(\sigma_{\mathrm{ac}}\right)$ of semiconductor composites is a helpful tool to understand the conduction mechanism in their respective alloys.

The high-temperature superconductor was first used in April 1986 to designate the new family of cupriteperovskite ceramic materials discovered by Johannes Gearg Bednorz and Karl Alexander Muller (Bednorz and Muller 1986).

The crystal structure of $\mathrm{YBa}_{2} \mathrm{Cu}_{3} \mathrm{O}_{7}$ (Y123) is characterized by the arrangement of copper-oxygen plan and copper-oxygen chains Fig. 1 (Jorgensen et al. 1987). The sequence of YBCO layers in the crystal is as follows:
$\mathrm{CuO}-\mathrm{BaO}-\mathrm{CuO}_{2}-\mathrm{Y}-\mathrm{CuO}_{2}-\mathrm{BaO}$ (Capponi et al. 1987). The planes of $\mathrm{CuO}_{2}$ with Yttrium atoms between the copper-oxygen planes separate the layers of the perovskite structure of YBCO. This structure gives rise to a large anisotropy in normal conducting and super conducting properties, as electrical current is involved by holes induced in the oxygen sites of $\mathrm{CuO}_{2}$ sheets. The electrical conduction is highly anisotropic with a much higher conductivity parallel to $\mathrm{CuO}_{2}$ plane than in the vertical direction.

Therefore, in the present work, nano-magnetic metal oxides, namely, $\mathrm{Mn}_{3} \mathrm{O}_{4}, \mathrm{Co}_{3} \mathrm{O}_{4}$, and $\mathrm{Cr}_{2} \mathrm{O}_{3}$ with different concentrations ranging from 0.1 to $0.5 \mathrm{wt} . \%$ have been chosen as doping in $\mathrm{YBCO}$ superconductors to improve the electrical properties of YBCO. The literature survey on dielectric studies demonstrate that relatively very few research works have been recorded on dielectric and ac electrical conductivity studies of YBCO systems.

Dielectric measurements of $\mathrm{YBCO}+X$ (where $X=0.1$, $0.2,0.3,0.4$, and $0.5 \mathrm{wt} . \%$ ) of each metal oxides have been carried out in the frequency range of $50 \mathrm{~Hz}$ to 5 $\mathrm{MHz}$ at temperature range 25 to $120^{\circ} \mathrm{C}$. The dependence of the dielectric constant $\varepsilon^{\prime}$, dielectric loss $\varepsilon^{\prime \prime}$ with frequency and temperature as well as concentration is discussed. Frequency- and composition-dependent ac conductivity has been studied for the aforementioned prepared samples.

\section{Experimental details \\ Preparing nano-metal oxides}

Nano-metal oxides $\left(\mathrm{Mn}_{3} \mathrm{O}_{4}, \mathrm{Co}_{3} \mathrm{O}_{4}\right.$, and $\left.\mathrm{Cr}_{2} \mathrm{O}_{3}\right)$ have been prepared by the co-precipitation method as described prior in our early studies (Bhargava et al. 1998; El-Hofy and Salama 2008; El-Hofy and Salama 2010). The chemical used was of analytical grade and used without further purification. Manganese chloride $\left(\mathrm{MnCl}_{2} \cdot 4 \mathrm{H}_{2} \mathrm{O}\right)$, cobalt chloride $\left(\mathrm{CoCl}_{2} \cdot 6 \mathrm{H}_{2} \mathrm{O}\right)$, chromium chloride $\left(\mathrm{CrCl}_{3} \cdot 6 \mathrm{H}_{2} \mathrm{O}\right)$, and oxalic acid $\left(\mathrm{C}_{2} \mathrm{H}_{2} \mathrm{O}_{4} \cdot 2 \mathrm{H}_{2} \mathrm{O}\right)$ were purchased from Sigma-Aldrich company with purity $99.5 \%$.

\section{Doping YBCO with nano-metal oxides}

YBCO powder is prepared by the solid-state reaction formulation by mixing stoichiometric amounts of $\mathrm{Y}_{2} \mathrm{O}_{3}$, 


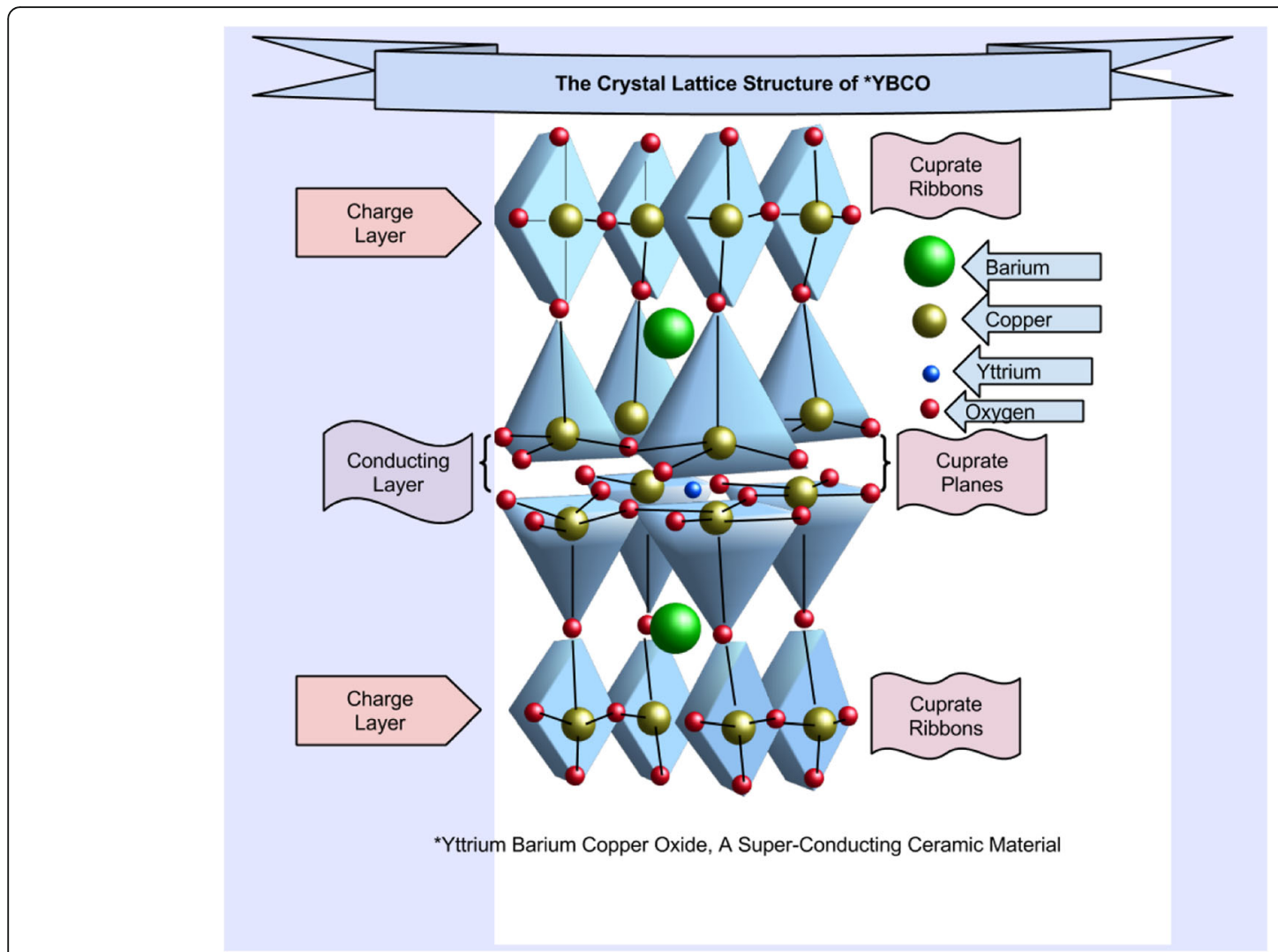

Fig. 1 The crystal structure of $\mathrm{YBCO}$

$\mathrm{BaCO}_{3}$, and $\mathrm{CuO}$ followed by grinding, calcinations, and sintering as previously described in details of our previous work (Salama et al. 2015).

A series of polycrystalline composite samples of $\mathrm{YBCO}+x$ where $x=0.1,0.2,0.3,0.4$, and $0.5 \mathrm{wt} . \%$ of each metal oxide $\left(\mathrm{Mn}_{3} \mathrm{O}_{4}, \mathrm{Co}_{3} \mathrm{O}_{4}\right.$, and $\left.\mathrm{Cr}_{2} \mathrm{O}_{3}\right)$ were mixed separately and pressed into pellets. The pellets were sintered according to the same curve of heat treatment as referenced (Salama et al. 2016a).

\section{Dielectric and ac electrical conductivity measurement}

Dielectric and electrical conductivity measurements have been done with HiOki LCR-Hi-Tester (3532-50) in the frequency range of 50 to $5 \mathrm{MHz}$ and temperature from room temperature to $120^{\circ} \mathrm{C}$. For this study, YBCO samples were pressed into cylindrical pellet forms with a diameter of $10 \mathrm{~mm}$ and thickness of about $1.2 \mathrm{~mm}$ under a uniform load of 5 tons using hydraulic press. The disc of the sample is placed between the electrodes of the LCR meter. The signal voltage level was kept at $0.02 \mathrm{~V}$.

Under dielectric studies, we measure the electrical properties of a material as a function of frequency. In our experiments, the real and imaginary parts of the complex dielectric permittivity, $\varepsilon^{*}\left(\varepsilon^{*}=\varepsilon-j \varepsilon^{\prime}\right)$ were obtained with the assumption that studied cell is equivalent to a circuit consisting of an ideal capacitance in parallel with a pure (ohmic) resistance $R_{\mathrm{p}}$.

The real part of the dielectric function (constant $\varepsilon^{\prime}$ ) of sample powders was calculated from the measured capacitance at all temperatures and frequencies in accordance with the following equation (Hipple 1966),

$$
\varepsilon^{\prime}=\left(C_{\mathrm{p}} d / \varepsilon_{\mathrm{o}} A\right)
$$

where $C$ is the capacitance, $d$ is the thickness, $A$ is the area, and $\varepsilon_{\mathrm{o}}$ is the permittivity of free space equal to $8.85 \times 10^{-12} \mathrm{~F} / \mathrm{m}$.

The dielectric loss tangent (El-Halawany and Salama 2009) defines the part of the power transformed into thermal energy that is observed by the material in the presence of the electric field, and the energy loss may be expressed in terms of phase defect angle $\delta$, so that

$$
\tan \delta=\varepsilon^{\prime \prime} / \varepsilon^{\prime}
$$

Under dielectric studies, we measure the capacitance of undoped YBCO sample and that doped with different concentrations of magnetic nano-metal oxides as a function of frequency and temperature. Studying dielectric properties aids in the definition of two essential electrical characteristics of materials. The first one is the 
capacitive insulating nature which is responsible for electrical charge storage and the second one is the conduction natural which is responsible for electrical charge transfer.

The ac electrical conductivity $\left(\sigma_{\mathrm{ac}}\right)$ was calculated from the measured resistance at the same temperature and frequency. The conductivity was calculated using the relation

$$
\sigma_{\mathrm{ac}=} L / R_{\mathrm{p}} a
$$

where $R_{\mathrm{p}}$ is the sample resistance, $a$ is the crosssectional area of the sample, and $L$ the sample thickness.

\section{Results}

\section{Dielectric studies of undoped YBCO}

The dielectric properties of undoped YBCO ceramics at $50 \mathrm{~Hz}$ in temperature range from room temperature to $120^{\circ} \mathrm{C}$ were studied. The variation of dielectric constant $\varepsilon^{\prime}$ and dielectric loss $\varepsilon^{\prime \prime}$ with frequency is shown in Fig. 2. Undoped YBCO has a dielectric constant equal to $6.99 \times 10^{6}$ at $50 \mathrm{~Hz}$ at room temperature which is increased gradually with temperature till it reaches to its maximum temperature at $120^{\circ} \mathrm{C}$; this value is orders of magnitude higher than those of SDM, Materials possessing a dielectric constant $>10^{5}$.

\section{Dielectric studies of doped YBCO samples}

Generally, the values of dielectric constant $\varepsilon^{\prime}$ and dielectric loss $\varepsilon^{\prime \prime}$ decrease with an increase in frequency and increase with an increase of temperature for all prepared YBCO ceramic samples. The values of $\varepsilon^{\prime}$ and $\varepsilon^{\prime \prime}$ collapse from a maximum value at low frequencies to become weakly frequency-dependent, and finally, at microwave frequency, a constant value is attained Fig. 3 . The values of dielectric constants for audio and microwave frequencies are given in Table (1).

\section{Frequency and composition dependence of ac electrical conductivity}

The ac conductivity is studied for undoped YBCO and doped $\mathrm{YBCO}$ with $0.1 \mathrm{wt} . \%$ of nano-metal oxide of $\mathrm{Cr}_{2} \mathrm{O}_{3}, \mathrm{Co}_{3} \mathrm{O}_{4}$, and $\mathrm{Mn}_{3} \mathrm{O}_{4}$ samples. $\sigma_{1}(\omega)$ is typically specified to the hopping conduction, and ac conductivity has a power law behavior in terms of frequency $(\omega)$.The power law exponents (s) obtained from the least square line fits of Fig. $5(\mathrm{a}-\mathrm{d})$ and the hopping frequency data are reported in Table 3. It is evident that the exponent $\mathrm{s}$ is less than unity and decreases modestly with increasing temperature.

The change in microwave conductivity of the studied samples with frequency $(50 \mathrm{~Hz}-5 \mathrm{MHz})$ is shown in Fig. 5. It is observed that for all the samples, the

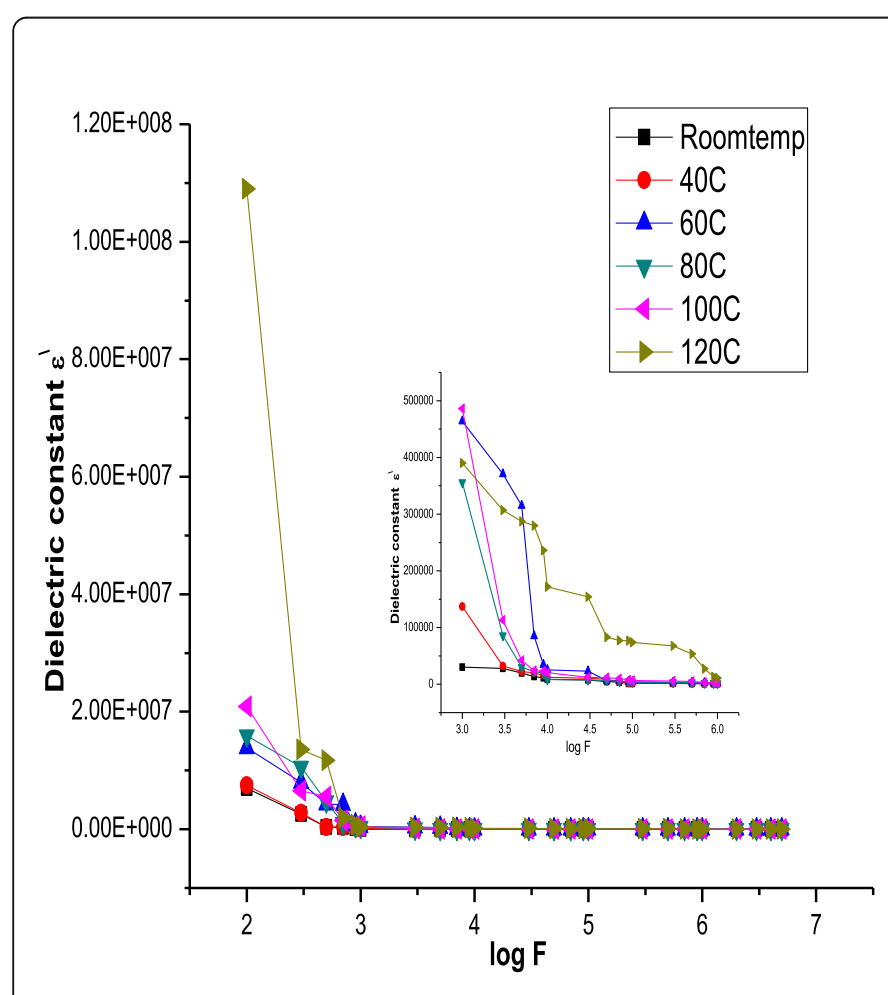

a

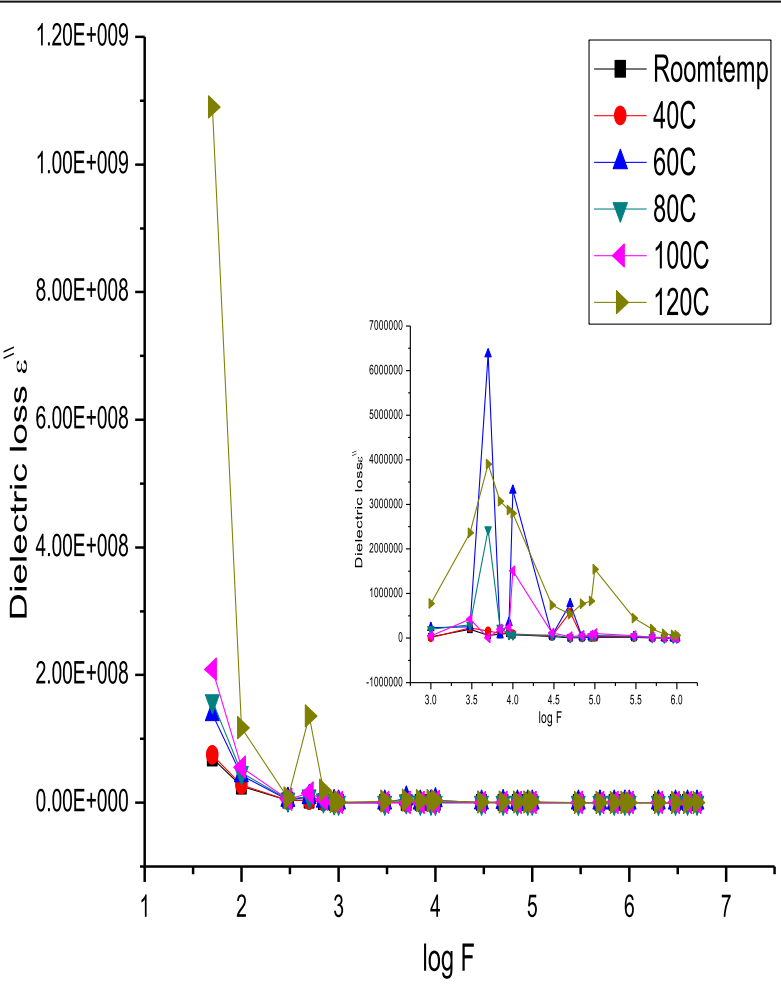

b

Fig. 2 The variation of dielectric constant $\varepsilon^{\prime}(\mathbf{a})$ and dielectric loss $\varepsilon^{\prime \prime}(\mathbf{b})$ as a function of frequency at different temperatures for undoped YBCO 


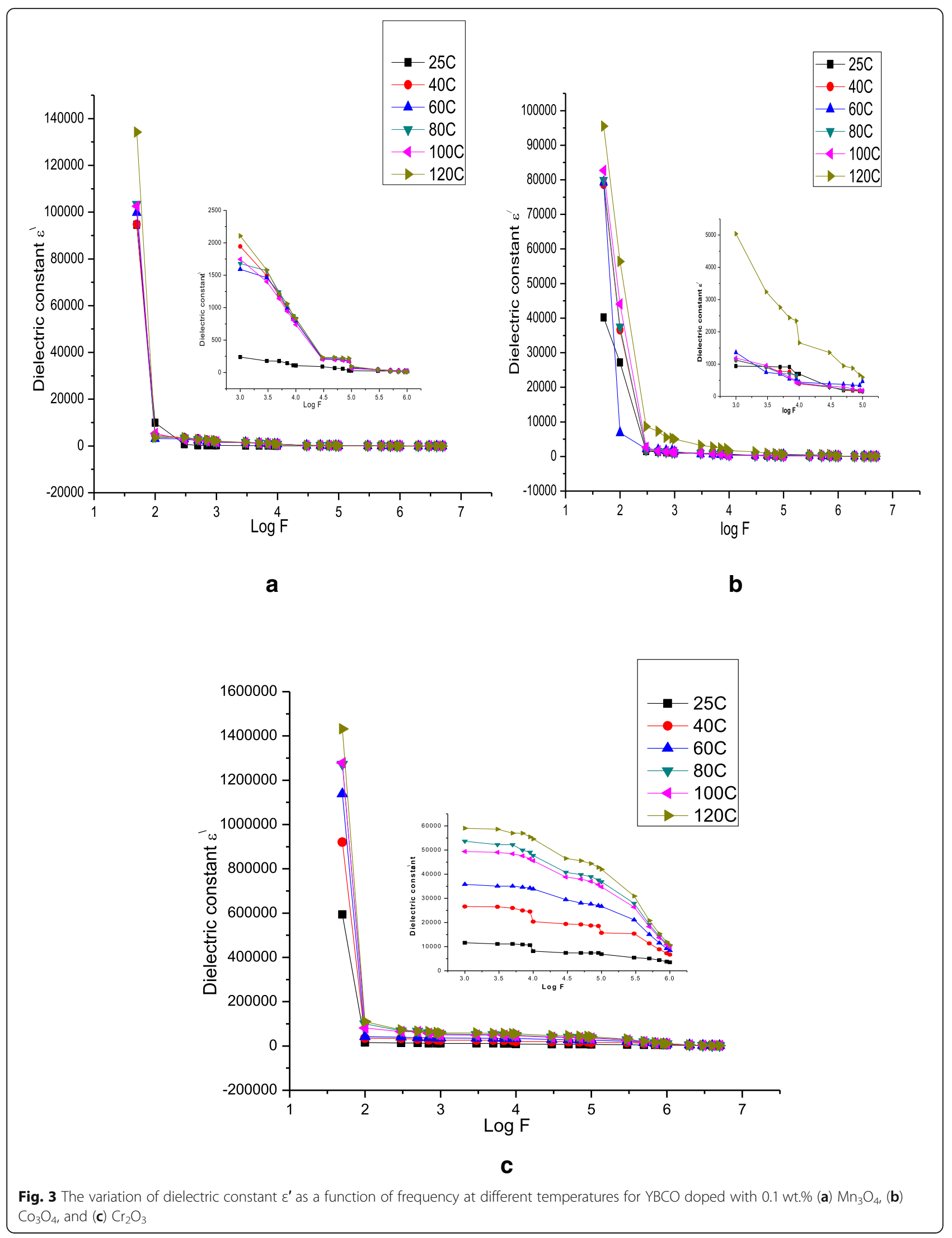


Table 1 Dielectric constant $\varepsilon^{\prime}$ for doped YBCO ceramic samples at $50 \mathrm{~Hz}$ and $1 \mathrm{MHz}$ at room temperature

\begin{tabular}{|c|c|c|c|c|c|c|}
\hline \multirow{2}{*}{$\begin{array}{l}\text { Sample } \\
\text { YBCO }+x\end{array}$} & \multicolumn{2}{|l|}{$\mathrm{Mn}_{3} \mathrm{O}_{4}$} & \multicolumn{2}{|l|}{$\mathrm{CO}_{3} \mathrm{O}_{4}$} & \multicolumn{2}{|l|}{$\mathrm{Cr}_{2} \mathrm{O}_{3}$} \\
\hline & $50 \mathrm{~Hz}$ & $1 \mathrm{MHz}$ & $50 \mathrm{~Hz}$ & $1 \mathrm{MHz}$ & $50 \mathrm{~Hz}$ & $1 \mathrm{MHz}$ \\
\hline$X=0.1$ & $9.45 \times 10^{4}$ & $1.55 \times 10^{1}$ & $4.02 \times 10^{4}$ & $2.23 \times 10^{1}$ & $1.13 \times 10^{6}$ & $8.38 \times 10^{3}$ \\
\hline$x=0.2$ & $1.17 \times 10^{4}$ & $1.33 \times 10^{1}$ & $3.83 \times 10^{5}$ & $5.25 \times 10^{1}$ & $6.54 \times 10^{5}$ & $3.85 \times 10^{3}$ \\
\hline$X=0.3$ & $1.36 \times 10^{6}$ & $2.51 \times 10^{3}$ & $3.01 \times 10^{3}$ & $4.54 \times 10^{1}$ & $1.23 \times 10^{6}$ & $1.05 \times 10^{4}$ \\
\hline$X=0.4$ & $2.14 \times 10^{5}$ & $4.76 \times 10^{2}$ & $3.35 \times 10^{3}$ & $3.98 \times 10^{1}$ & $6.21 \times 10^{2}$ & $2.37 \times 10^{1}$ \\
\hline$X=0.5$ & $7.95 \times 10^{4}$ & $5.50 \times 10^{2}$ & $1.03 \times 10^{5}$ & $7.98 \times 10^{1}$ & $5.92 \times 10^{5}$ & $5.09 \times 10^{1}$ \\
\hline
\end{tabular}

conductivity increases with temperature and depends on the doped metal oxide. The values of $\sigma_{\mathrm{ac}}$ at $5 \mathrm{MHz}$ varied from -0.4 to 1.2 for undoped YBCO, from -0.98 to -0.75 for 0.1 wt. $\% \mathrm{Mn}_{3} \mathrm{O}_{4}$-YBCO sample, from -0.25 to 0.2 for 0.1 wt. $\% \mathrm{Co}_{2} \mathrm{O}_{3}$-YBCO sample, and from -0.4 to 0.6 for $0.1 \mathrm{Wt} . \% \mathrm{Cr}_{3} \mathrm{O}_{4}-\mathrm{YBCO}$.

\section{Discussion}

\section{Dielectric studies of undoped YBCO}

It is noticeable that the dielectric constant and dielectric loss of YBCO decrease with increase in frequency and increase with increase of temperature. It should be noted that the dielectric constant of YBCO increases at $50 \mathrm{~Hz}$ from $6.99 \times 10^{6}$ at room temperature to $1.09 \times 10^{8}$ at $120^{\circ} \mathrm{C}$.

The calculated dielectric constant of undoped YBCO is orders of extent higher than any form of barium titanite $\left(\sim 10^{3}\right)$ which represents the most important result of this study. This represents a new category of dielectrics, super dielectric materials (SDM), with dielectric constants at low frequency $(50 \mathrm{~Hz})$ greater than $10^{5}$. These materials exhibit an intrinsic dielectric constant greater than $10^{5}$ at very low frequency (Jayalakshmi and Balasubramanian 2008). The measured ultrahigh dielectric constants is pivotal in paving a path to develop a classic electrostatic capacitor as an alternative to supercapacitors for electrical energy storage/power delivery without the challenges associated with the rise of volume and weight. Such capacitors can be used to replace batteries in hybrid vehicles. There are different mechanisms for generating ultrahigh dielectric constant $\varepsilon^{\prime}$ (SDMs); the most prominent mechanisms that can give rise to enhanced values of the dielectric constant are ferroelectricity, charge-density wave formation, hopping charge transport, the metal-insulator transition, and various derivations of the interface effect (Lunkenheimer et al. 2010). As we reported previously in the introductory section, the unique crystal structure of YBCO contains a layered crystal structure consisting of one or more $\mathrm{CuO}_{2}$ layers. Each copper atom in a $\mathrm{Cu}-\mathrm{O}_{2}$ plane has a strong covalent bond, in a nearly square planar order, with four oxygen atoms at a distance of $1.9 \AA^{\prime}$. (the $\mathrm{Cu}-\mathrm{O}$ bond strength). Also, the copper present in the mixed valence state includes a partial oxidation of $\mathrm{Cu}^{2+}$ to $\mathrm{Cu}^{3+}$; therefore, there is a charge transfer to and from the $\mathrm{CuO}_{2}$ layers near the metal-insulator phase boundary. The insulating interfaces can occur at the surface of the sample, due to the formation of a Schottky diode at the electrode/sample contact or due to a thin insulating surface layer with slightly different stoichiometry (e.g., oxygen content). Also, internal interfaces can arise, e.g., from grain boundaries in ceramic samples or planar crystal defects (e.g., twin boundaries).

The variation of loss factor $\left(\varepsilon^{\prime \prime}\right)$ with frequency for undoped YBCO ceramics sample is shown in Fig. 2b. The variation is much prominent at lower frequencies. It has been observed that $\varepsilon^{\prime \prime}$ decreases with frequency, which may be arising from charge carriers existing in the ceramic sample which can migrate for some distance under the influence of an applied electric field. When such carriers are inhibited at the electrodes, a space charge region is activated which leads to a substantial increase in $\varepsilon^{\prime \prime}$ toward high frequencies (Sang et al. 2016) which gives rise to the observed relaxation of the entire curve.

\section{Dielectric studies of doped YBCO samples}

It is well known that for a polar material, the decrease of $\varepsilon^{\prime}$ with increasing frequency can be explained by the subscription of several types of polarization (Shukla and Dwivedi 2016) (space charge, orientation, electronic and ionic polarization). This polarization resulted from the changes in valence states of cations and space charge polarization. At higher frequencies, the dielectric constant becomes independent of frequency due to the lag of electric dipoles to follow the fast variation of the alternating applied electric field. In fact, electronic polarization takes place at high frequencies up to $10^{16}$ $\mathrm{Hz}$ due to the displacement of the valence electrons relative to the positive nucleus whereas, ionic polarization which occurs at $10^{3} \mathrm{~Hz}$ results from the shift of negative and positive ions with respect to each other. The third type of polarization is dipole polarization which arises in a material containing molecules with permanent electric dipole moment that can change the orientation in the direction of the applied electric field. This type of polarization occurs at frequencies near $10^{10} \mathrm{~Hz}$. The last type of polarization called 
space charge polarization results from impedance mobile charge carriers by interfaces. This type of polarization arises at frequency range from $0 \mathrm{~Hz}$ to $10^{3} \mathrm{~Hz}$. The sum of the previously mentioned four types of polarization results in the total polarization of the dielectric material (Hegab and El-Mallah 2009).

In the view of the obtained results of the present study recorded at Table 1 and 2, we can state the high values of dielectric constant $\varepsilon^{\prime}$ may be due to the interfacial effects within the YBCO crystal structure and doped metal oxide nano-powders and electronic and magnetic effect of each dopant.

(YBCO) $\mathrm{YBa}_{2} \mathrm{Cu}_{3} \mathrm{O}_{6+x}$ is known as a hightemperature superconductor. The optical and electronic properties of YBCO are characterized by its oxygen percentage (Poberaj and Michailovic 1992; Jahanzeb et al. 1997). For $x=1 \mathrm{wt} . \%, \mathrm{YBCO}$ has an orthorhombic structure and has metallic conductivity. It is superconductive when it is cooling under its critical temperature ( $\mathrm{Yu}$ and Heeger 1993). As $x$ is decreased to 0.5, a crystal structure transitions to a tetragonal structure with semiconducting properties as it exists in a fermi glass state. If $x$ is decreased below 0.3, YBCO becomes a Hubbard insulator with an energy gap on the order of $1.5 \mathrm{eV}$. As our previously published paper (Salama et al. 2016b), the prepared YBCO samples have a single-phase perovskite structure with orthorhombic structure. The lattice parameters of YBCO orthorhombic structure are $a=$ $3.823 \AA$, $b=3.885 \AA$, and $c=11.7 \AA$. There is no peak corresponding to any other compounds.

Figure 3 represents the variation of the dielectric constant $\varepsilon^{\prime}$ with a frequency at various temperatures for 0.1 wt.\% for each doping ceramic samples as delineated in this study. One can notice that the value of dielectric constant depends on the electrical and magnetic properties of each doping nano-metal oxide. For $0.1 \mathrm{wt} . \%$ $\mathrm{Mn}_{3} \mathrm{O}_{4}$, Fig. 3(a) manganese $(\mathrm{Mn})$ is a transition metal having multiple valences $2+, 3+, 4+, 5+, 6+, 7+$, etc., and hence, it forms a number of oxide systems such as $\mathrm{MnO}, \mathrm{MnO}_{2}, \mathrm{Mn}_{2} \mathrm{O}_{3}, \mathrm{Mn}_{2} \mathrm{O}_{5}, \mathrm{MnO}_{3}, \mathrm{Mn}_{3} \mathrm{O}_{7}$, and $\mathrm{Mn}_{3} \mathrm{O}_{4}$. Among these, $\mathrm{Mn}_{3} \mathrm{O}_{4}$ is the most stable of oxides with a magnetic moment of $5.27 \mu \mathrm{B}$. Also, $\mathrm{Mn}_{3} \mathrm{O}_{4}$ is a material with normal spinal structure containing a tetrahedral site occupied by $\mathrm{Mn}^{3+}$ cations (Ribeiro et al.
2015). Our previous work indicates that $\mathrm{Mn}_{3} \mathrm{O}_{4}$ is distributed over the entire surface of the granules as points in the nano-sized range. This unique structure is responsible for the high values of $\varepsilon^{\prime}$ appearing in Fig. 3(a) where $\varepsilon^{\prime}$ is varied from $9.45 \times 10^{5}$ to 15.5 at room temperature and varied from $1.34 \times 10^{5}$ to 9.242 at 1 $\mathrm{MHz}$ at $120^{\circ} \mathrm{C}$.

Figure 3(b) represents the variation of $\varepsilon^{\prime}$ for $0.1 \mathrm{wt} . \%$ $\mathrm{Co}_{3} \mathrm{O}_{4}$ doping $\mathrm{YBCO} . \mathrm{Co}_{3} \mathrm{O}_{4}$ has a magnetic moment equal to $3.26 \mu \mathrm{B}$, and it crystallizes in the cubic spinal structure which contains cobalt ions in two different oxidative states, $\mathrm{Co}^{2+}$ and $\mathrm{Co}^{3+}$. There is evidence that $\mathrm{Co}^{2+}$ ion has three unpaired $\mathrm{d}$ electrons whereas all the $\mathrm{d}$ electrons of $\mathrm{Co}^{3+}$ are paired. As a result, the $\mathrm{Co}^{3+}$ ions are not magnetic, while the $\mathrm{Co}^{2+}$ carries a magnetic moment. Its conductivity is a p-type with band gap values around $1.6 \mathrm{eV}$ (Shinde et al. 2006; Kim and Park 2003). In addition, TEM images and EDAX- analysis from our previous work suggests that $\mathrm{Co}_{3} \mathrm{O}_{4}$ is distributed over the entire surface of the granules as points in the nanosized range. Our previous evidence show the elevated values recorded for doped $\mathrm{YBCO}$ with $\mathrm{Co}_{3} \mathrm{O}_{4}$ where the values of $\varepsilon^{\prime}$ varied from $9.5 \times 10^{5}$ at $50 \mathrm{~Hz}$ to 13.24 at 1 $\mathrm{MHz}$ at room temperature; these values change from $7.8 \times 10^{4}$ at $50 \mathrm{~Hz}$ to 53.42 in ceramic samples doped with $\mathrm{Cr}_{2} \mathrm{O}_{3}$ Fig. 3(c). It is well known that $\mathrm{Cr}_{2} \mathrm{O}_{3}$ is a ptype semiconductor with a wide band gap $\left(\begin{array}{ll}E_{\mathrm{g}} & 3 \mathrm{eV}\end{array}\right)$. It has a rhombohedra crystal structure and a magnetic component. Also, from our aforementioned work, we concluded that $\mathrm{Cr}_{2} \mathrm{O}_{3}$ tends to merge through the structure between or covering the YBCO grains and may be responsible for the variable values of $\varepsilon^{\prime}$ from $1.138 \times 10^{6}$ at $50 \mathrm{~Hz}$ to $8.38 \times 10^{3}$ at $1 \mathrm{MHz}$ at room temperature and from $5.935 \times 10^{5}$ at $50 \mathrm{~Hz}$ to $3.53 \times 10^{3}$ at $1 \mathrm{MHz}$ at $120^{\circ} \mathrm{C}$. In values of $\varepsilon^{\prime}$ recorded for various doping levels, Tables 1 and 2 illustrate that $\varepsilon^{\prime}$ depends on the doping ratio which may be due to the transition of electrons between mixed valence of $\mathrm{Mn}^{3+} \leftrightarrow \mathrm{Mn}^{4+}, \mathrm{Co}^{3+} \leftrightarrow \mathrm{Co}^{4+}$, and $\mathrm{Cr}^{2+} \leftrightarrow \mathrm{Cr}^{3+}$. This phenomenon gives rise to space charge polarization and interfacial occurrences at low frequencies up to $10^{3} \mathrm{~Hz}$. In addition to the decrease of orientation, polarization decreases with increasing frequency as it takes more time than ionic and electronic polarization. Figure 4 shows that $0.3 \mathrm{wt} . \%$ of $\mathrm{Mn}_{3} \mathrm{O}_{4}$ and

Table 2 Dielectric constant $\varepsilon^{\prime}$ for doped $\mathrm{YBCO}$ ceramic samples at $50 \mathrm{~Hz}$ and $1 \mathrm{MHz}$ at $120^{\circ} \mathrm{C}$

\begin{tabular}{|c|c|c|c|c|c|c|}
\hline \multirow{2}{*}{$\begin{array}{l}\text { Sample } \\
\text { YBCO +x }\end{array}$} & \multicolumn{2}{|l|}{$\mathrm{Mn}_{3} \mathrm{O}_{4}$} & \multicolumn{2}{|l|}{$\mathrm{CO}_{3} \mathrm{O}_{4}$} & \multicolumn{2}{|l|}{$\mathrm{Cr}_{2} \mathrm{O}_{3}$} \\
\hline & $\overline{50 \mathrm{~Hz}}$ & $1 \mathrm{MHz}$ & $50 \mathrm{~Hz}$ & $1 \mathrm{MHz}$ & $50 \mathrm{~Hz}$ & $1 \mathrm{MHz}$ \\
\hline$x=0.1$ & $1.34 \times 10^{5}$ & 9.24 & $7.86 \times 10^{4}$ & $5.34 \times 10^{1}$ & $5.93 \times 10^{5}$ & $3.53 \times 10^{3}$ \\
\hline$x=0.2$ & $3.26 \times 10^{4}$ & 8.98 & $4.42 \times 10^{6}$ & $8.16 \times 10^{2}$ & $7.27 \times 10^{5}$ & $3.10 \times 10^{3}$ \\
\hline$X=0.3$ & $1.16 \times 10^{6}$ & $9.25 \times 10^{2}$ & $2.15 \times 10^{5}$ & $6.01 \times 10^{1}$ & $5.43 \times 10^{5}$ & $2.50 \times 10^{3}$ \\
\hline$x=0.4$ & $7.04 \times 10^{5}$ & $1.95 \times 10^{3}$ & $3.66 \times 10^{4}$ & $2.24 \times 10^{1}$ & $9.45 \times 10^{2}$ & $2.07 \times 10^{1}$ \\
\hline$X=0.5$ & $1.50 \times 10^{5}$ & $4.96 \times 10^{2}$ & $1.38 \times 10^{5}$ & $3.31 \times 10^{1}$ & $8.23 \times 10^{4}$ & $2.70 \times 10^{1}$ \\
\hline
\end{tabular}




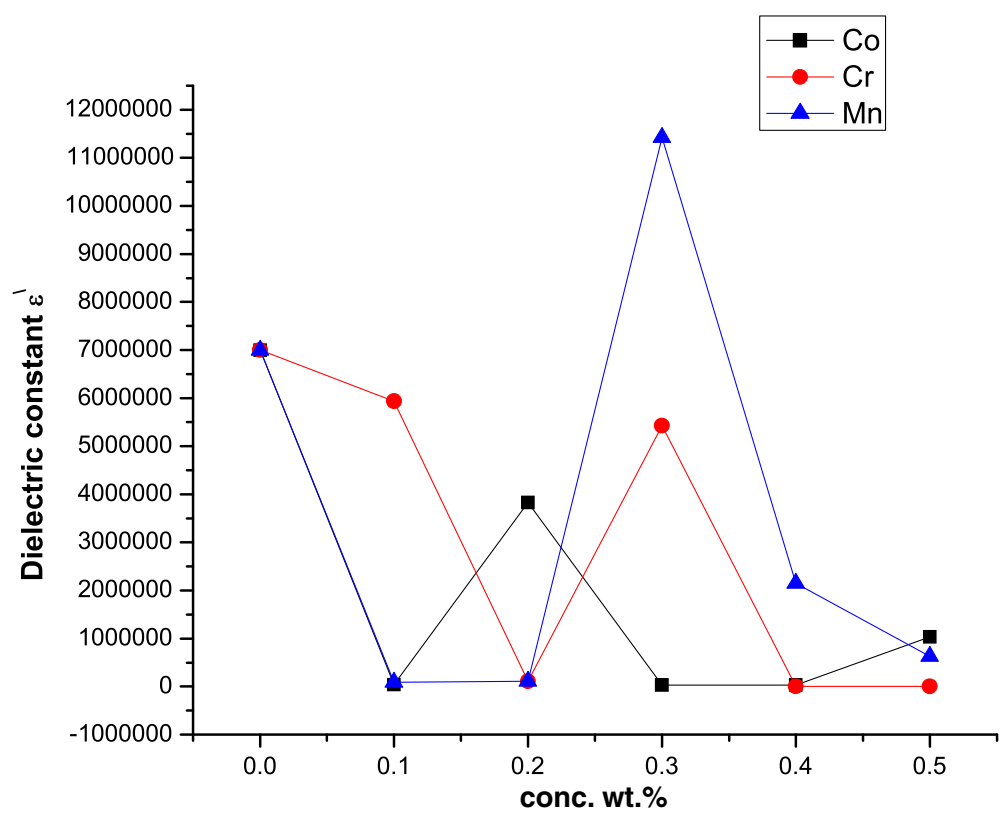

Fig. 4 The variation of dielectric constant $\varepsilon^{\prime}$ as a function of concentration at room temperatures for undoped YBCO and doped with different concentrations of $\mathrm{Mn}_{3} \mathrm{O}_{4}, \mathrm{CO}_{3} \mathrm{O}_{4}$, and $\mathrm{Cr}_{2} \mathrm{O}_{3}$

$\mathrm{Cr}_{2} \mathrm{O}_{3}$ doping $\mathrm{YBCO}$ ceramic samples have the highest values of $\varepsilon^{\prime}$ where it reached $1.36 \times 10^{6}$ and $1.23 \times 10^{6}$ for $\mathrm{Mn}_{3} \mathrm{O}_{4}$ and $\mathrm{Cr}_{2} \mathrm{O}_{3}$ at $50 \mathrm{~Hz}$, respectively, where $0.2 \mathrm{wt} . \%$ $\mathrm{Co}_{3} \mathrm{O}_{4} \varepsilon^{\prime}$ has the highest values of $3.83 \times 10^{5}$.

\section{Frequency and composition dependence of ac electrical conductivity}

Ac conductivity measurements are the most appropriate method to explain frequency dependence of electrical behavior of materials. The variation of ac conductivity $\left(\sigma_{\text {ac }}\right)$ with frequency at different temperatures for each sample is as delineated in Fig. 5a-d.

An attempt was made by Jonscher to explain this behavior using the following universal power law (AbdelKarim et al. 2017),

$$
\begin{gathered}
\sigma_{\mathrm{ac}}=\sigma_{\mathrm{dc}}+\sigma_{1}(\omega) \\
\sigma_{\mathrm{ac}}=\sigma_{\mathrm{dc}}+\mathrm{A} \omega^{\mathrm{s}}
\end{gathered}
$$

where $\sigma_{\mathrm{dc}}$ is a frequency-independent conductivity (connected to dc conductivity), $\sigma_{1}(\omega)$ is typically specified to the hopping conduction, and ac conductivity has a power law behavior in terms of frequency $(\omega)$. A is the pre-exponential factor dependent on temperature; $s$ is the exponent and can have a value between 0 and 1 . If the value of $s<1$, the hopping conduction is predominant, and if $s>1$, the conduction is through localized motion. The term $\mathrm{A} \omega^{\mathrm{s}}$ can be described on the basis of two carrier conduction mechanisms:
- Quantum mechanical tunneling (QMT) through the barrier separating the localized sites

- Correlated barrier hopping ( $\mathrm{CBH})$ over the same barrier

In reference to Fig. 5a-d, there are two frequencydependent regions for all the studied ceramic samples, the low-frequency one, where $\sigma_{\mathrm{ac}}$ is independent of frequency, and the high-frequency region, where dispersion occurs. A change in the slope of ac conductivity with frequency is detected at the temperature where the grain resistance controls over the grain boundary resistance. The frequency at which the slope changes correspond with the polaron hopping of charged species with increasing temperature. The charged species which are increased at grain boundaries have sufficient energy to jump over the barrier, thereby increasing the conductivity. The frequency at which this transition occurs is called the hopping frequency $\left(\omega_{\mathrm{p}}\right)$ which follows the following relation:

$$
\sigma_{(\omega)}=K \omega_{\mathrm{p}}\left[1+\left(\omega / \omega_{\mathrm{p}}\right)\right]^{\mathrm{n}}
$$

The frequency independent behavior of the conductivity in the low-frequency region becomes sensitive in the high-frequency region. Upon increasing temperature, the hopping frequency shifts toward a higher frequency, and, of note, this value depends on the kind of doping metal oxide. 


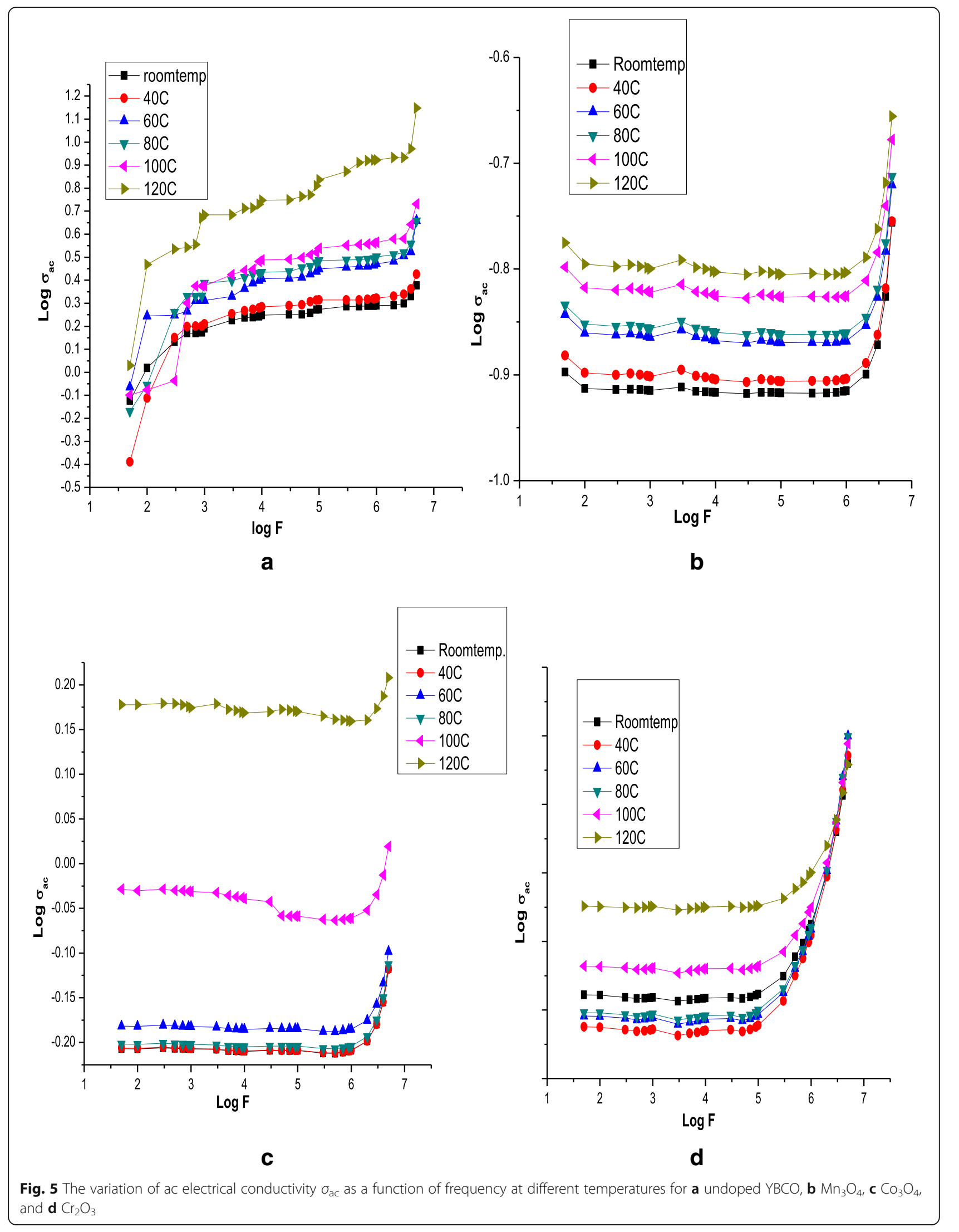


Table 3 The values of $\mathrm{s}$ and hopping frequency for the study composites at room temperature and $120^{\circ} \mathrm{C}$

\begin{tabular}{|c|c|c|c|c|c|c|c|c|c|}
\hline \multirow{3}{*}{$\begin{array}{l}\text { Sample } \\
\text { YBCO } \\
+x \\
\end{array}$} & \multicolumn{3}{|l|}{$\mathrm{Mn}_{3} \mathrm{O}_{4}$} & \multicolumn{3}{|l|}{$\mathrm{CO}_{3} \mathrm{O}_{4}$} & \multicolumn{3}{|l|}{$\mathrm{Cr}_{2} \mathrm{O}_{3}$} \\
\hline & & Room temp. & $120^{\circ} \mathrm{C}$ & & Room temp. & $120^{\circ} \mathrm{C}$ & & Room temp. & $120^{\circ} \mathrm{C}$ \\
\hline & $\omega_{p}$ & $S$ & $S$ & $\omega_{p}$ & $S$ & $S$ & $\omega_{p}$ & $S$ & $S$ \\
\hline YBCO & $6.28 \times 10^{6}$ & 0.237 & 0.107 & $6.28 \times 10^{6}$ & 0.237 & 0.107 & $6.28 \times 10^{6}$ & 0.237 & 0.107 \\
\hline$X=0.1$ & $6.28 \times 10^{6}$ & 0.205 & 0.191 & $6.28 \times 10^{6}$ & 0.194 & 0.064 & $6.28 \times 10^{5}$ & 0.133 & 0.077 \\
\hline$X=0.2$ & $6.28 \times 10^{6}$ & 0.191 & 0.190 & $6.28 \times 10^{6}$ & 0.285 & 0.135 & $6.28 \times 10^{5}$ & 0.264 & 0.189 \\
\hline$X=0.3$ & $6.28 \times 10^{6}$ & 0.222 & 0.237 & $6.28 \times 10^{6}$ & 0.962 & 0.277 & $6.28 \times 10^{5}$ & 0.543 & 0.195 \\
\hline$X=0.4$ & $3.14 \times 10^{6}$ & 0.048 & -0.245 & $6.28 \times 10^{6}$ & 0.291 & 0.175 & $6.28 \times 10^{5}$ & 0.687 & 1.334 \\
\hline$X=0.5$ & $6.28 \times 10^{6}$ & 0.423 & 0.407 & $6.28 \times 10^{6}$ & 0.187 & 0.172 & $6.28 \times 10^{6}$ & 0.263 & 0.212 \\
\hline
\end{tabular}

The power law exponents (s) obtained from the least square line fits as seen in Fig. $5 \mathrm{a}-\mathrm{d}$ and the hopping frequency data are reported in Table 3. It is clear that the exponent $\mathrm{s}$ is less than that of the unity and decreases modestly with increasing temperature. This supported the assumption that the conduction mechanism in the studied samples is the correlated barrier hopping $(\mathrm{CBH})$ model (Ben Taher et al. 2015).

Otherwise, at lower frequencies, the grain boundaries are more effective, and hence, the electron hopping between $\mathrm{M}^{2+} \leftrightarrow \mathrm{M}^{3+}$ ions are less at lower frequencies.

\section{Conclusion}

The primary finding in this paper is of empirical investigation. YBCO which is a high-temperature superconductor has a high dielectric constant $\varepsilon^{\prime}$ ranged from $6.99 \times 10^{6}$ at room temperature to $1.09 \times 10^{8}$ at $120^{\circ} \mathrm{C}$. This value is at least three orders of magnitude greater than any previously studied composites which suggest this perovskite ceramic material can be used to create electrostatic capacitors with energy far more efficient than those of the best electrode double layer capacitors (EDLC).

Upon doping with different ratios of magnetic nano-metal oxides of $\mathrm{Mn}_{3} \mathrm{O}_{4}, \mathrm{Co}_{3} \mathrm{O}_{4}$, and $\mathrm{Cr}_{2} \mathrm{O}_{3}$, this ultrahigh dielectric constant is consistent. However, the value of $\varepsilon^{\prime}$ is changed with the doping ratio along with the value of the magnetic moment for each metal oxide. The highest value recorded for $0.3 \mathrm{wt} . \%$ $\mathrm{Mn}_{3} \mathrm{O}_{4}$ is equal to $1.36 \times 10^{6}$ whereas the lowest is at 0.2 wt. $\% \mathrm{Co}_{3} \mathrm{O}_{4}$ is equal to $3.83 \times 10^{5}$. The ac conductivity measurements with frequency lead us to conclude that the conduction mechanism in the studied samples is attributed to the correlated barrier hopping (CBH) model. To the author's knowledge, the dielectric and ac conductivity studies at radio and microwave frequencies have been discussed here for the first time. The microwave conductivity of samples have values dependent on the doping values of metal oxides.

\section{Acknowledgements}

The authors acknowledge the national research center labs and physics department labs, faculty of science, Menoufia University for the facilities it provides during this work.

\section{Authors' contributions}

AHS and AMY developed the concepts of the study. AHS, YSR, and MK design and prepared the materials. MK collected the literature research. AHS and AMY analyzed and interpreted the data and prepared the manuscript. AHS wrote the manuscript. AHS and AMY revised the manuscript. All authors read and approved the manuscript.

\section{Funding}

This work was funded by NRC, Egypt, under the project no. AR110902.

Availability of data and materials

The authors declare the data supporting the findings of this study are available within the article.

Ethics approval and consent to participate

Not applicable

Consent for publication

Not applicable

Competing interests

The authors declare that they have no competing interests.

\section{Publisher's Note}

Springer Nature remains neutral with regard to jurisdictional claims in published maps and institutional affiliations.

\section{Author details}

${ }^{1}$ Physical Chemistry Department, National Research Centre, El-Buhouth St., Dokki, Cairo 12622, Egypt. ${ }^{2}$ Inorganic Chemistry Department, National Research Centre, El-Buhouth St., Dokki, Cairo 12622, Egypt. ${ }^{3}$ Physics Department, Faculty of Science, Menoufia Unveristy, Shiben El-Koom, Egypt.

Received: 28 October 2018 Accepted: 15 May 2019

Published online: 07 June 2019

\section{References}

Abdel- Karim AM, Salama AH, El- Samahy FA, El- SM, Osman FH (2017) Some dielectric properties of novel nano-s-triazine derivatives. J PhysOrg Chem 30:3703

Abdel-All A (1998) Ac conductivity of $\left(\mathrm{As}_{2} \mathrm{Te}_{3}\right)_{(100-x)} \mathrm{Ge}-\mathrm{x}$ bulk glassy system. J Mater Sci Technol 14(3):247-250

Atiya $\mathrm{HE}$ (2014) Electrical conductivity and dielectric relaxation of bulkSe $\mathrm{Bi}_{70} \mathrm{Bi}_{(30-x)} \mathrm{Te}_{\mathrm{x}}$ $x=(0,15)$ chalogenide glasses. J Non-Cryst Solids 391:83-90

Bednorz JG, Muller KA (1986) Possible high Tc superconductivity in the Ba- LaCu- O system. Z Physik B, Condensed Matter 64:189-193

Ben Taher Y, Oueslati A, Maaloul NK, Khirouni K, Gargouri M (2015) Conductivity study and correlated barrier hopping $(\mathrm{CBH})$ conduction mechanism in diphosphate compound. Appl Phys A Mater Sci Process 120(4):1537-1543 
Bhargava A, Alarco JA, IDR M, Page D, llyushechkin A (1998) Synthesis and characterization of nanoscale magnesim oxide powders and their application in thick films of $\mathrm{Bi}_{2} \mathrm{Sr}_{2} \mathrm{CaCu}_{2} \mathrm{O}_{8}$. Mater Lett 34(3-6):133-142

Bitar RA, Arafah DE (1998) Processing effects on the structure of CdTe, CdS andSnO $\mathrm{O}_{2}$ thin films. Sol Energy Mater Sol Cells 51(1):83-93

Capponi JJ, Chaillout C, Hewat AW, Lejay P, Marezio M, Nguyen N, Raveau B, Soubeyroux JL, Tholence JL, Tournier R (1987) Structure of 100 Ksuperconductor $\mathrm{Ba}_{2} \mathrm{YCu}_{3} \mathrm{O}_{7}$ between $(5 \div 300) \mathrm{K}$ by Neutron Powder Diffraction. Europhys Lett 3(12):1301-1308

El-Halawany NR, Salama AH (2009) Synthesis, Characterization and electrical properties of novel conducting co-polymer nanocomposities via minimemulsion polymerization technique. Egypt J Chem 52(4):537-549

El-Hofy M, Salama AH (2008) Synthesis and characterization of Ba defective ZnONano-particles, Defect and Diffus. Forum 280-28:11-18

El-Hofy M, Salama AH (2010) Voltage switch of nano-size zinc oxide ceramic defect barium. Defect and Diffus Forum. 307:21-26

Hegab NA, El-Mallah HM (2009) Ac conductivity and dielectric properties of amorphous $\mathrm{Te}_{42} \mathrm{As}_{36} \mathrm{Ge}_{10} \mathrm{Si}_{12}$ glasses. Acta Phys Pol A 116:1048-1152

Hipple ARV (1966) Dielectrics and waves. the MIT press (Student edition), Cambridge, $p 284$

Jahanzeb A, Travers CM, Butler DP, Celik-Kutler Z, Gray JE (1997) Strong pyroelectric response in semiconducting $\mathrm{Y}-\mathrm{Ba}-\mathrm{Cu}-\mathrm{O}$ and its application to uncooled infrared detection. Appl Phys lett 70(26):3495-3497

Jayalakshmi M, Balasubramanian K (2008) Simple capacitors to supercapacitors-An overview. Int J Electrochem Sci 3(11):1196-1217

Jorgensen JD, Beno MA, Hinks DG, Soderholm L, Volink J, Hitterman RL, Grace JD, Schullerlvan K, Segre CU, Zhang K, Kleefisch MS (1987) Oxygen ordering and the orthorhombic - to - tetragonal phase transition inY $\mathrm{Ba}_{2} \mathrm{Cu}_{3} \mathrm{O}_{7-x}$. Phys Rev B 36(7):3608-3616

Jyothy PV, Arun Kumar KV, Karthika S, Rajesh R, Unnikrishnan NV (2010) Dielectric and Ac- conductivity studies of CdSe nanocrystals doped sol-gel silica mtrics. J Alloys Compounds 493:223-226

Kim KJ, Park YR (2003) Optical investigation of charge - transfer transitions in spinel $\mathrm{CO}_{3} \mathrm{O}_{4}$. Solid State Commun 127(1):25-28

Long AR (1982) Frequency - dependent loss in amorphous semiconductors. Advs Phys 31:553-637

Lunkenheimer P, Krohns S, Riegg S, Ebbinghaus SG, Reller A, Loidl A (2010) Colossal dielectric constant in transition metal oxides. Eur Phys J Special Topics 180:61-89

Poberaj I, Michailovic D (1992) Pyroelectric effect measurements in $\mathrm{YBa}_{2} \mathrm{Cu}_{3} \mathrm{O}_{6}+$ yand $\mathrm{La}_{2} \mathrm{CuO}_{4}$ materials. Ferroelectrics. 128:197-200

Ram IS, SinghR K, Singh P, Singh K (2013) Effect of Pb addition on dielectric relaxation in $\mathrm{Se}_{80} \mathrm{In}_{2} \mathrm{O}$ glassy system. J Alloys Compounds. 552:480-485

Redwan MA, Aly EH, Soliman LI, El-Shazely AA, Zayed HA (2003) Characteristics of $\mathrm{n}-\mathrm{Cd}_{0.9} \mathrm{Zn}_{0.1} \mathrm{~S} / \mathrm{P}-\mathrm{CdTe}$ hetero-junctions. Vacuum. 69(4):545-555

Ribeiro RAP, Delazaro SR, Pianero SA (2015) Density functional theory applied to magnetic materials: $\mathrm{Mn}_{3} \mathrm{O}_{4}$ at different hybrid functionals. J Magn Magn Mater 391:166-171

Salama AH, El-Hofy M, Rammah YS, Elkhateeb M (2016b) The influence of magnetic nano metal oxides doping on structure and electrical properties of YBCO superconductor. Adv Nat Sci: Nanosci NanoTechnol 7:015011

Salama AH, El-Hofy M, Rammah YS, Elkhatib M (2015) Effect of magnetic and nonmagnetic nano metal oxides doping on the critical temperature of aYBCO superconductor. Adv Nat Sci: Nanosci Nanotechnol 6:045013

Salama AH, El-Hofy M, Rammah YS, Elkhatib M (2016a) Pinning behavior of Nano Nonmagnetic $\mathrm{CuO}, \mathrm{SnO}_{2}$ and Magnetic Mn2O3substitutionsn in YBCO Bulk Superconductors. Interceram 65(1-2):017-024

Sang L, Zhang Y, Wang J, Zhao Y, Chen YT (2016) Correlation of the depletion layer with Helmholtz layer in the anatase $\mathrm{TiO}_{2}-\mathrm{H}_{2} \mathrm{O}$ interface via molecular dynamics simulations. Phys Chem Chem Phys 18(22):15427-15435

Sedeek K, Adam A, Wahab LA, Hafez M (2003) Dielectric relaxation inGe $\mathrm{G}_{1-x} \mathrm{Se}_{2} \mathrm{~Pb}_{x}$ $(x=0,0.2$ and 0.6$)$ nano- crystalline system. Mater Chem Phys 85(1):20-26

Seyam MAM (2001) Dielectric relaxation in polycrystalline thin films of $\ln _{2} \mathrm{Te}_{3}$. Appl Surf Sci 181:128-138

Shinde VR, Mahadik SB, Gujar TP, Lokhande CD (2006) Supercapactive cobalt oxide $\left(\mathrm{CO}_{3} \mathrm{O}_{4}\right)$ thin films by spray pyrolysis. Applied Surface Science 252(20):7487-7492

Shukla N, Dwivedi DK (2016) Dielectric relaxation and Ac conductivity studies of $\mathrm{Se}_{90} \mathrm{Cd}_{10-x} \mathrm{In} \times \mathrm{g}$ glassy alloys. J Asian Ceramic Soc 4(2):178-184

Yu G, Heeger AJ (1993) High - Tc superconductors: disordered metals with pairing via polarizability from localized states near the mobility edge. Phys Rev B 48(9):6492-6498

\section{Submit your manuscript to a SpringerOpen ${ }^{\circ}$ journal and benefit from:}

- Convenient online submission

- Rigorous peer review

- Open access: articles freely available online

High visibility within the field

- Retaining the copyright to your article

Submit your next manuscript at $\boldsymbol{\nabla}$ springeropen.com 